\title{
Overworked and Overpaid: Failure in the Market for Job Experience
}

\author{
Marko Terviö \\ University of California, Berkeley* \\ marko@haas.berkeley.edu
}

February 13, 2009

\begin{abstract}
In medicine, law, consulting, and many other careers, a significant proportion of human capital is created through industry-specific learning-bydoing. In the absence of long-term wage contracts, if learning effects are sufficiently large, then young workers should face a negative wage in return for high future wages. However, if workers are liquidity constrained, then young workers compete away these returns to experience by working inefficiently hard. This inefficiency results in higher lifetime earnings and also causes older workers to exert too little effort. The model can explain "career concerns" in professions where effort and ability are observable.
\end{abstract}

*Mailing address: Haas School of Business; 545 Student Services Bldg, \#1900; Berkeley, CA 94720-1900. I thank Ben Hermalin, Michael Katz, Jonathan Leonard, David I. Levine, Alex Mas, Matthew Mitchell, Juuso Välimäki, and Johan Walden for insightful comments. 


\section{Introduction}

In many professions, learning-by-doing arguably contributes as much or even more to lifetime human capital formation than formal education or on-the-job training. This paper explores what happens when workers cannot pay the efficient market price for job experience that enhances productivity. The problems that arise when workers are not able to pay for general (as opposed to firm-specific) on-the-job training are well known, but the same question for learning-by-doing has been neglected as a potential source of market failure-probably because it is a passive by-product of working, while training is an active and thus a more tangible way for worker improvement. ${ }^{1}$ But despite being costless in the accounting sense, unavoidable on-the-job learning in fact carries an economic cost: the opportunity cost that someone else could be working in the same job instead. This cost is missed by traditional models of learning that treat the price of output as exogenous.

In Sherwin Rosen's seminal paper (1972) the labor market was analyzed as an implicit market for jobs, where the implicit price of a job is the wage discount that workers accept in return for jobs with learning content. This paper can be interpreted as an investigation of what happens when young workers are unable to pay the full implicit price of jobs in Rosen's sense. In Rosen's model, the price of output is exogenous and firms decide which types of jobs to supply to the market. Jobs are costly because workers have to work with real resources-machinery, materials, subordinates-for learning to occur. However, if one were merely to add a liquidity constraint to Rosen's model, then the costliest types of jobs would simply not be provided and learning would be slower than is efficient. In the

\footnotetext{
${ }^{1}$ For a discussion of the literature on market failure in on-the-job training, see Acemoglu and Pischke (1999).
} 
current paper, the jobs of young and old workers are technologically identical, and they constitute an entire profession or an "industry." The industry produces a unique good with its own demand curve, so even if the learning content of a job is so valuable that the implicit price of jobs is beyond the means of young workers, someone has to hire inexperienced workers in equilibrium—or else soon there would be no experienced workers either! As it turns out, the price of output and the effort level of young workers will have to adjust until the output of inexperienced workers is valuable enough to cover the complementary costs of production associated with the job.

I use a model with perfect information and perfect competition to analyze the effects of worker liquidity constraints in the presence of general (or "industryspecific") learning-by-doing. I show that industries with strong learning-by-doing effects-those with a steep upward trend in productivity over the career-induce the young to exert inefficiently high effort as an entry payment into careers that promise higher returns to experience. Moreover, older workers will slack off and exert too little effort. The reason is that, in industries where the effort choices over the lifetime are distorted, output ends up being produced at an inefficiently high cost. The higher price of output makes the more experienced workers richer, and they use some of their increased wealth to consume more leisure (or to enjoy a more leisurely work pace). This distorted age profile of effort will tend to decrease the growth in earnings over the career, thus dissipating the observed (monetary) returns to experience. Workers in such a distorted career are compensated by higher lifetime wages, but total welfare is lower than what could be achieved under long-term contracts or if workers could self finance the costs of production.

The model suggests that workers in professions where a high fraction of the stock of human capital is created through learning-by-doing will be the most "overworked and overpaid," i.e., have the highest wages and lifetime effort costs compared to peers with similar qualifications in other professions. The empirical implications of the model concern differences across industries and institutions. 
If there were an exogenous change in the level of imperfections, for example, if longer wage contracts suddenly became enforceable, then we should expect relative wages to decrease in sectors with strong learning-by-doing effects-and this would be a sign of improved efficiency and welfare. These sectors would also be likely to show an increase in monetary returns to experience, meaning a steeper age-earnings profile. However, for a given institutional setup and a given level of imperfections, the model does not generate any unusual predictions about wage dynamics - changes in wages simply reflect changes in individual output.

The idea that much of the modern workforce is involved in a futile "rat race" between workers has some popular credence, see for example Juliet Schor's (1992) best-seller "The Overworked American" or the recent media campaign "Take Back Your Time." ${ }^{2}$ The typical behavioral explanation for overwork is based on competition for status: if people care about the relative level of consumption compared to their peers, then the desire to "keep up with the Joneses" leads to excessive labor supply - and everyone could be better off if labor supply could be restricted in a coordinated fashion. ${ }^{3}$ (If status was measured in leisure time as opposed to consumption then presumably the opposite would be true). However, the story of the rat race proposed in this paper is most emphatically not due to uncoordinated individuals somehow valuing material goods too much relative to leisure. In fact, the nature of the inefficiency is such that the society ends up getting less material goods as well: the utilization of human capital, and therefore the production of output is inefficient in sectors with strong learning-by-doing, leading to a reduction in the supply of consumption goods. The workers in a sector with strong learning effects get more of the goods and less of the leisure than would be efficient, but, at the level of the economy, the rat race reduces the total amount of output.

\footnotetext{
${ }^{2}$ By the Center for Religion, Ethics, and Social Policy, see http://www.simpleliving.net/timeday/.

${ }^{3}$ There are other theoretical explanations, e.g, Hamermesh and Slemrod (2006) explain "workaholism" as a (potentially rational) form of addiction.
} 
Earlier models that result in excessive effort by young workers have been based on asymmetric information. In the classic career concerns model employers observe workers' past output but not its breakdown by the contributions of effort and ability, and young workers exert excessive effort to influence the employers' assessment of their ability and thus increase their future pay levels (Holmström 1982). This "signal jamming" results in a rat race that, in equilibrium, does not fool anyone. Excessive effort also results in a setup where effort is observable but effort costs are not, as types with low cost use excessive effort as a signal to differentiate themselves from high cost types prior to an irreversible admission into an income-sharing partnership (Landers, Rebitzer and Taylor 1996). ${ }^{4}$

In the absence of asymmetric information there would be no motivation for anyone to use inefficient actions in trying to influence one's perceived type. Observable effort-like hours worked — cannot be used to "jam the signal" about true ability. And temporary overwork cannot help gain rents out of underwork tomorrow if the employer is not locked into to paying an above-market wage in the future. I show that neither asymmetric information nor lock-in is necessary for a rat race. Interestingly, there have been efforts in the medical profession to restrict work hours by young workers - the medical residents—and they have overwhelmingly supported the restrictions. ${ }^{5}$ (Note that in a signalling setup, the insiders should not support such restrictions.) The need for coordinated action suggests that some kind of a rat race may be going on, even though the hours are observable and the medical residents are not in a risky up-or-out situation like potential law partners.

\footnotetext{
${ }^{4}$ In Ghatak, Morelli and Sjöström (2001) excess effort induced by a credit constraint is defined relative to an inefficiently low level (shirking). There some young workers work hard and save in order to later become capitalists and earn rents on scarce capital; the credit constraint is thus beneficial in second-best fashion by partially offsetting a moral hazard problem.

${ }^{5}$ The 80-hour cap on weekly hours imposed in 2003 by ACGME (Accreditation Council for Graduate Medical Education) is routinely binding, and often neglected; see http://www.hourswatch.org/.
} 
In practice, the information problems behind career concerns and the predictable returns to experience of this model are of course not mutually exclusive phenomena. What is common with this paper and the models of asymmetric information is the inability of workers to pay up-front for entry. If young workers were able to take a sufficiently negative wage then there would be no problem - just like in asymmetric information setups, if workers were able to post a sufficiently large bond, then efficiency would not be disturbed. However, in the setup of this paper, the payment required from young workers is not going to be bounded by the outside wage; I will show that it includes a share of the non-labor costs of production, and that share is increasing in the rate of learning-by-doing. In professions with steep learning curves, entering workers would have to be able to finance most of the complementary costs of production for the first-best solution to be attained.

The next section introduces the key idea with the simplest possible model, where effort is fixed. Section 3 analyzes the main model, Section 4 discusses why work hours regulation would decrease welfare, and Section 5 shows how a linear income tax can improve welfare. Limitations and possible generalizations of the model are discussed in Section 6, and Section 7 concludes the paper.

\section{A Model without Effort}

The environment is a spot labor market for a competitive industry of firms that combine workers with other inputs and take the market price of output $p$ as given. Firms incur a fixed cost of production $\phi$ per job, so the zero profit condition ties down the equilibrium wage of a worker who produces $y$ units of output as

$$
w=p y-\phi .
$$

This relation will be used throughout the analysis without any explicit reference to entry or exit of firms. It is understood that the industry faces a downward sloping demand for its output, so higher price of output is associated with lower 
output and lower consumer surplus. (Whether this translates into more or less employment and revenue in the industry is outside the model - that would depend on the elasticity of demand and on the possible change in output per worker). It is not necessary to interpret the equilibrium wage as a piece-rate or hourly-wage contract, only that the equilibrium wage level must be consistent with the level of effort that goes with the position. In practice, even when there is no explicit contract on output, different positions come with different expectations for how much is expected of the workers.

Workers live for two periods, and their output is exogenously higher in their second period, $y_{2}>y_{1}>0$, due to general (or "industry-specific") learning-bydoing. Throughout this paper, only stationary equilibrium is considered, so the average output of workers over the lifetime, denoted by $\bar{y} \equiv\left(y_{1}+y_{2}\right) / 2$, is also the average output of the workers in the industry at any given time. Lifetime utility is

$$
V\left(x_{1}, x_{2}\right)=u\left(x_{1}\right)+u\left(x_{2}\right)
$$

where the consumption levels in the two periods are $x_{1}, x_{2} \geq 0$ and $u$ is a utility function with the standard properties. ${ }^{6}$

Young workers are able to costlessly borrow an amount $b$ against their future wages. Recall that the labor market equilibrium and zero profit conditions are both inherent in the wages $w_{t}=p y_{t}-\phi$. The smoothed consumption levels are therefore

$$
x_{1}=p y_{1}-\phi+b, x_{2}=p y_{2}-\phi-b .
$$

Setting $b=0$ corresponds to a total inability to borrow, and $b \equiv p\left(y_{2}-y_{1}\right) / 2$ to the ability to completely smooth consumption over lifetime.

Young workers must be indifferent between entering or going to the outside sector, where they could earn a constant wage $w_{0}$. The equilibrium condition

$$
{ }^{6} u^{\prime}>0, u^{\prime \prime}<0, \lim _{c \rightarrow 0} u(c)=-\infty .
$$


that defines the price of output, and subsequently wages and consumption, is the condition of no lifetime rents:

$$
u\left(p y_{1}-\phi+b\right)+u\left(p y_{2}-\phi-b\right)=2 u\left(w_{0}\right) .
$$

With unconstrained borrowing, consumption is equalized across periods and only depends on average output over the lifetime: $x_{1}=x_{2}=p \bar{y}-\phi$. The closed form solution for the equilibrium price is

$$
p^{*}=\left(w_{0}+\phi\right) / \bar{y}
$$

This price is equal to the average cost of production. Wages are

$$
w_{t}^{*}=\left(w_{0}+\phi\right) y_{t} / \bar{y}-\phi, \quad t=1,2
$$

and consumption is equal to the outside wage $w_{0}$ in both periods. The amount of borrowing required by a young worker is

$$
b^{*}=\frac{w_{2}^{*}-w_{1}^{*}}{2}=\left(w_{0}+\phi\right)\left(\frac{y_{2}-y_{1}}{2 \bar{y}}\right) .
$$

Note that the required borrowing is by no means restricted by $2 w_{0}$, the lifetime income in the outside sector. The market value of job experience depends on the cost of complementary factors of production that the worker gets to work with. The young worker should pay for a fraction of the costs of production-a fraction that describes the contribution of learning-by-doing to lifetime output. When the borrowing ability is below $b^{*}$ the workers are constrained and the efficient outcome is unattainable. With constrained borrowing the equilibrium price (and subsequently the wages) is in general only defined implicitly by equation (4).

Proposition 1 When effort levels are fixed, then a lower ability to borrow leads to higher wages in both periods. 
Proof. Differentiate the equilibrium condition (4) with respect to $p$ and $b$ and solve for the slope of the implicit function $p(b)$ :

$$
\begin{array}{r}
\left\{u^{\prime}\left(x_{1}\right) y_{1}+u^{\prime}\left(x_{2}\right) y_{2}\right\} \mathrm{d} p+\left\{u^{\prime}\left(x_{1}\right)-u^{\prime}\left(x_{2}\right)\right\} \mathrm{d} b=0 \\
\Longrightarrow \frac{\mathrm{d} p}{\mathrm{~d} b}=-\frac{u^{\prime}\left(x_{1}\right)-u^{\prime}\left(x_{2}\right)}{u^{\prime}\left(x_{1}\right) y_{1}+u^{\prime}\left(x_{2}\right) y_{2}}<0
\end{array}
$$

This inequality holds for all $b \in\left[0, b^{*}\right)$, because then $x_{1}<x_{2}$ and the difference of marginal utilities in the numerator is positive. Only at $b=b^{*}$ does the numerator become zero as $x_{1}=x_{2}$. The result that wages $w_{t}=p y_{t}-\phi$, are decreasing in the borrowing capability follows directly from the price of output being decreasing in the borrowing capability $b$.

Intuitively, a lower borrowing ability lowers utility since marginal utility of consumption in the first period is lower than in the second period when the earnings are higher. To attract workers to this sector, the price of output (and thus the value of experience) must increase. This is an inefficient way of attracting workers into the sector because most of the increase in income accrues to workers when they are already experienced and have a relatively high income to begin with.

What are the welfare effects of a decrease in the borrowing ability? From the point of view of the workers, the inefficiency is first visible as the welfare lost due to low consumption of young workers. Workers are compensated in the form of higher lifetime wages to induce them to enter the industry, but consumers are not compensated: welfare is reduced as the price of output is increased. Lower quantity demanded leads to fewer workers in the industry, each making more money than before; total revenue and the sum of wages in the industry could increase or decrease depending on the elasticity of demand.

When could this inefficiency be substantial? We can see from (5) that the price of output is increasing in the non-labor cost of production $\phi$. This means that the required amount of borrowing for full efficiency to be attained is increasing in $\phi$. 
The young workers should literally pay to work if

$$
\begin{aligned}
w_{1}^{*} & =\left(\frac{\phi+w_{0}}{\bar{y}}\right) y_{1}-\phi<0 \\
& \Leftrightarrow \frac{y_{1}}{\bar{y}}<\frac{\phi}{\phi+w_{0}} .
\end{aligned}
$$

The impact of a credit constraint is large when the effect of experience on output is large (meaning that the left side of 10 is small), and when the non-labor costs of production are relatively high (right side of 10). As is intuitive, the borrowing constraint will bite the hardest when the difference that experience makes to output is high, and when the cost of production is high.

\section{The Model with Effort}

Now let's add the assumption that effort matters for output. The output profile of a worker who supplies effort $e_{1}$ when young and $e_{2}$ when old is

$$
\begin{aligned}
& y_{1}=\theta(1-\delta) e_{1}, \\
& y_{2}=\theta(1+\delta) e_{2},
\end{aligned} \quad \theta>0, \quad \delta \in(0,1), e_{t} \in[0,1]
$$

where $\theta$ is the average productivity over the career, and $\delta$ is the learning effect or the slope of the learning curve. At times it will be more convenient to denote the ability in career period $t$ by $\theta_{t}$, so that $y_{t}=\theta_{t} e_{t}$.

The key assumption about preferences is that workers have diminishing marginal utility both for consumption and for lack of effort or "leisure" (which can mean a more leisurely pace at work). Consumption and leisure are both imperfectly substitutable over time. Logarithmic period utility function in consumption $x_{t}$ and leisure $\left(1-e_{t}\right)$ is adopted:

$$
u\left(x_{t}, e_{t}\right)=\alpha \log \left(x_{t}\right)+(1-\alpha) \log \left(1-e_{t}\right), \quad \alpha \in(0,1) .
$$

The discount rate is normalized at zero, giving lifetime utility as the sum $\sum_{t=1}^{2} u\left(x_{t}, e_{t}\right)$. This form implies a separable, convex effort cost, and guarantees 
a positive level of consumption and leisure throughout the career. The relation of wages and consumption will depend on the possible liquidity constraint (more of which later); due to concave utility, consumption will be as even across the periods as allowed by the ability to borrow.

The equilibrium consists of an effort profile $\left\{e_{1}, e_{2}\right\}$ that maximizes lifetime utility while taking as given the price of output, and of output price $p$ at which the maximized lifetime utility equals that from the outside option, $2 u_{0}$. Throughout this paper, only stationary equilibrium is considered, so half of the workforce consists of "young" and "old" workers each and the average output of workers over the lifetime is also the average output per worker in the industry at any given time. (It will be clear that, in equilibrium, no one would wish to enter or exit the industry mid-career).

It will be convenient to denote the market value of the per-period endowment of labor by

$$
z(p)=p \theta-\phi .
$$

This would be the average per-period wage and consumption for an individual if she were to work at the maximum level $e_{t}=1$ in both periods. Superscript $(*)$ will refer to equilibrium values in the unconstrained case, and superscript (0) in the liquidity constrained case.

\section{Efficient Benchmark}

With unconstrained borrowing capability, workers simply consume half of their lifetime income in each period. Combining (1) and (11), this means that consumption is

$$
x\left(e_{1}, e_{2} \mid p\right)=(p / 2)\left(\theta_{1} e_{1}+\theta_{2} e_{2}\right)-\phi
$$

in both periods. The workers choose $e_{1}$ and $e_{2}$ to maximize

$$
\sum_{t=1}^{2} u\left(x\left(e_{1}, e_{2} \mid p\right), e_{t}\right) \text {. }
$$


Efforts and consumption can be solved as a function of price in standard CobbDouglas fashion, with $\alpha$ defining the fraction of the endowment of labor spent on consumption. Optimal choices by the workers can be expressed as

$$
\begin{aligned}
1-e_{t}^{*}(p) & =\frac{(1-\alpha)}{p \theta_{t}} z(p), \quad \text { for } t=1,2, \\
x^{*}(p) & =\alpha z(p) .
\end{aligned}
$$

The price of leisure in period $t$ is $p \theta_{t}$, the opportunity cost in terms of forgone consumption. ${ }^{7}$ Finally, the equilibrium price of output is pinned down by the indifference condition of entering workers

$$
\begin{aligned}
p^{*} & =\left\{p \text { st. } V^{*}(p)=2 u_{0}\right\} \\
\text { where } V^{*}(p) & =u\left(x^{*}(p), e_{1}^{*}(p)\right)+u\left(x^{*}(p), e_{2}^{*}(p)\right) .
\end{aligned}
$$

Combining (1) and (11) with (16), the amount of borrowing necessary to equalize consumption across periods is

$$
\begin{aligned}
b^{*}=\frac{p^{*} y_{2}^{*}-p^{*} y_{1}^{*}}{2} & =p^{*}\left(\frac{\theta_{2} e_{2}^{*}\left(p^{*}\right)-\theta_{1} e_{1}^{*}\left(p^{*}\right)}{2}\right) \\
& =\delta\left(z\left(p^{*}\right)+\phi\right) .
\end{aligned}
$$

This is the implicit price of the job in Rosen's sense. Young workers "pay" $b$ * and earn it back when old. The average wage-which includes the compensating differential for the efficient effort supply-must equal the per-period consumption from (17). The wage profile is therefore $\left\{w_{1}^{*}, w_{2}^{*}\right\}=\left\{\alpha z\left(p^{*}\right)-b^{*}, \alpha z\left(p^{*}\right)+b^{*}\right\}$.

The implicit price of jobs $b^{*}$ can be interpreted in the following way. The efficient solution requires young workers to finance a proportion $\delta$ of the complementary costs of production, $\phi$. This proportion reflects the contribution of worker learning to industry output in the following sense: If there were no learning after

\footnotetext{
${ }^{7}$ If $\theta_{1}$ is close enough to zero ( $\delta$ is close enough to unity) then $e_{1}^{*}=0$ becomes binding. For analytical convenience, we assume $\delta$ to be "small enough" to preclude this, although all qualitative results hold even in this precluded region.
} 
all (or if workers exited the industry mid-career), then potential output per worker would be lower by $\theta-\theta_{1}=\delta \theta$, i.e., by a proportion $\delta$ of the actual average. In addition, young workers have to borrow a portion $\delta$ of the opportunity cost of their own labor; this is a form of consumption smoothing that they would undergo even if other production costs were nil. Note that if the cost of production is high relative to the value of labor, then young workers should literally pay to work even under moderate rates of learning-by-doing.

If the borrowing ability is below $b^{*}$ then workers are liquidity constrained and the efficient equilibrium is not possible.

\section{Liquidity Constraint}

Under constrained borrowing ability, $b \in\left[0, b^{*}\right)$, the workers are unable, at the margin, to transform second period effort into first period consumption. The consumption level in each period depends on borrowing $b$, but not directly on the other period's effort choice. Consumption profile is now

$$
\tilde{x}_{1}\left(e_{1} \mid p\right)=p \theta_{1} e_{1}-\phi+b \quad \text { and } \quad \tilde{x}_{2}\left(e_{2} \mid p\right)=p \theta_{2} e_{2}-\phi-b .
$$

Lifetime utility can be written as

$$
u\left(\tilde{x}_{1}\left(e_{1} \mid p\right), e_{1}\right)+u\left(\tilde{x}_{2}\left(e_{2} \mid p\right), e_{2}\right)
$$

so the worker's maximization problem in $\left(e_{1}, e_{2}\right)$ separates into two independent problems, one for each period.

Worker's optimal solution again involves the consumption share $\alpha$, but the available endowment of effective labor is now considered separately for each period. Denoting the market value of the endowment of labor by career period $z_{t}(p)=p \theta_{t}-\phi$, the optimal choices are

$$
\begin{aligned}
& 1-e_{1}^{0}(p)=\frac{(1-\alpha)}{p \theta_{1}}\left(z_{1}(p)+b\right), \\
& 1-e_{2}^{0}(p)=\frac{(1-\alpha)}{p \theta_{2}}\left(z_{2}(p)-b\right) . \\
& x_{1}^{0}(p)=\alpha\left(z_{1}(p)+b\right), \\
& x_{2}^{0}(p)=\alpha\left(z_{2}(p)-b\right) .
\end{aligned}
$$


Again, the equilibrium price is such that maximized lifetime utility equals the utility from a career elsewhere.

$$
\begin{aligned}
p^{0} & =\left\{p \text { st. } \tilde{V}(p)=2 u_{0}\right\}, \\
\text { where } \tilde{V}(p) & =u\left(x_{1}^{0}(p), e_{1}^{0}(p)\right)+u\left(x_{2}^{0}(p), e_{2}^{0}(p)\right) .
\end{aligned}
$$

The equilibrium wage profile can then be written as $\left\{w_{1}^{0}, w_{2}^{0}\right\}=\left\{\alpha z_{1}\left(p^{0}\right)-\right.$ $\left.(1-\alpha) b, \alpha z_{2}\left(p^{0}\right)+(1-\alpha) b\right\}^{8}$

Since there is free entry by identical workers and firms in equilibrium, welfare can only be affected by the consumer side, namely by the price of output. The distortion of a lower borrowing ability must lower welfare, as seen in the following Lemma.

Lemma 2 A lower ability to borrow leads to a higher price of output.

Proof. Differentiate the equilibrium condition (25) with respect to $p$ and $b$, use the envelope theorem to eliminate terms involving $\partial \tilde{V} / \partial e_{t}$, and solve for the slope of the implicit function $p^{0}=p(b)$ :

$$
\begin{array}{r}
\left\{u_{x}\left(x_{1}\right) y_{1}+u_{x}\left(x_{2}\right) y_{2}\right\} \mathrm{d} p+\left\{u_{x}\left(x_{1}\right)-u_{x}\left(x_{2}\right)\right\} \mathrm{d} b=0 \\
\Longrightarrow \frac{\mathrm{d} p^{0}}{\mathrm{~d} b}=-\frac{u_{x}\left(x_{1}\right)-u_{x}\left(x_{2}\right)}{u_{x}\left(x_{1}\right) y_{1}+u_{x}\left(x_{2}\right) y_{2}}<0
\end{array}
$$

This inequality holds for all $b \in\left[0, b^{*}\right)$, because then $x_{1}<x_{2}$ and the difference of the marginal utilities in the numerator is positive. At the limit of $b=b^{*}$ the numerator becomes zero as $x_{1}=x_{2}$.

To understand the mechanism behind the price distortion, note that a lower borrowing constraint decreases utility when young, and increases utility when old, and that these effects must wash out in terms of utility in equilibrium as the value of the outside opportunity is fixed. As the better paid old workers already have a lower marginal utility of consumption, this will increase the average level of consumption and therefore the cost of labor.

\footnotetext{
${ }^{8}$ Note that $b$ is now a parameter, whereas $b^{*}$ was an equilibrium outcome.
} 
Proposition 3 A lower ability to borrow leads to higher effort when young, and lower effort when old.

Proof. Taking the derivative of $e_{2}^{0}$ from (23) gives

$$
\frac{\partial e_{2}^{0}}{\partial b}=\left(\frac{1-\alpha}{p^{0} \theta_{2}}\right)\left(1-\frac{\phi+b}{p^{o}} \frac{\mathrm{d} p^{0}}{\mathrm{~d} b}\right),
$$

which is positive, since $\mathrm{d} p^{0} / \mathrm{d} b<0$ by Lemma 2 . To obtain the result for $e_{1}^{0}$, take the first-order condition with respect to $e_{1}^{0}$ in (25) and differentiate implicitly to obtain

$$
\begin{aligned}
& \left\{-\frac{\alpha\left(p^{0}\right)^{2} \theta_{1}}{x_{1}^{0}}-\frac{1-\alpha}{\left(1-e_{1}^{0}\right)^{2}}\right\} \mathrm{d} e_{1}+ \\
& \left\{\left(\frac{\alpha \theta_{1}}{x_{1}^{0}}-\frac{\alpha p^{0} \theta_{1}^{2} e_{1}^{0}}{x_{1}}\right) \frac{\mathrm{d} p^{0}}{\mathrm{~d} b}-\frac{\alpha p^{0} \theta_{1}}{x_{1}^{0}}\right\} \mathrm{d} b=0 \\
\Longleftrightarrow & \frac{\mathrm{d} e_{1}^{0}}{\mathrm{~d} b}=-\frac{\frac{\alpha \theta_{1}}{x_{1}^{0}}\left\{\frac{\mathrm{d} p^{0}}{\mathrm{~d} b}-\frac{p^{0}}{x_{1}^{0}}\left(\theta_{1} e_{1}^{0} \frac{\mathrm{d} p^{0}}{\mathrm{~d} b}+1\right)\right\}}{\text { negative term }\}} .
\end{aligned}
$$

Therefore $1+\theta_{1} e_{1}^{0}\left(\mathrm{~d} p^{0} / \mathrm{d} b\right)>0$ is a sufficient condition for $\mathrm{d} e_{1}^{0} / \mathrm{d} b<0$. To verify that this holds, plug in the expression for $\mathrm{d} p^{0} / \mathrm{d} b$ from (8), use $y_{t}=\theta_{t} e_{t}$ and $u_{x}\left(x_{t}\right)=\alpha / x_{t}$, and rearrange:

$$
\begin{array}{r}
-y_{1} \frac{\alpha / x_{1}-\alpha / x_{2}}{\alpha y_{1} / x_{1}+\alpha y_{2} / x_{2}}+1>0 \\
\Longleftrightarrow \frac{y_{1}+y_{2}}{x_{2}}>0 .
\end{array}
$$

Intuitively, entering an industry with a steep learning curve cannot be a better deal than any other career. The rents for experienced workers must be dissipated in the utility of the inexperienced workers, and it happens on both available margins: via lower consumption and via higher effort. The tighter the liquidity constraint on the young, the less able they are to use money to compete for the future rents to experience; instead they end up supplying more effort. On the other hand, 
the supply of effort by the old is reduced, because the increased price of output increases the value of their endowment of effective labor, and because the lower borrowing ability "forces" them to be richer (by having a smaller debt to repay). They use some of this increase in wealth to consume more leisure. However, they still produce and earn more than the young.

Proposition 4 A lower ability to borrow leads to higher wage when young and to higher average wage.

Proof. Using (24), average wage is $\alpha(p \theta-\phi)$. This depends on $b$ only via the price of output, and is decreasing in it via Lemma 2. As for the first-period wage, differentiate $w_{t}=p \theta_{t} e_{t}-\phi$ with respect to $b$ :

$$
\frac{\partial w_{t}^{0}}{\partial b}=\theta_{t}\left(\frac{\mathrm{d} p^{0}}{\mathrm{~d} b} e_{t}^{0}+p^{0} \frac{\mathrm{d} e_{t}^{0}}{\mathrm{~d} b}\right)
$$

This is unambiguously negative for $t=1$, because both of the derivatives on the right-hand side are negative, by Lemma 2 and Proposition 3 respectively.

A stricter borrowing constraint increases the earnings of the young because the price effect and the direct effect of higher effort go in the same direction. As for the average wage, higher lifetime earnings must be there to compensate for higher lifetime effort costs - this is the feature behind the title of the paper. By contrast, the effect of the borrowing constraint on the earnings of the old would be ambiguous, because the higher price of output and the lower effort work to opposing directions-consider (32) at $t=2$. For a small distortion (borrowing ability close to $b^{*}$ ) the first-order decrease in effort must dominate, as the change in the price of output is of second order near the optimal borrowing amount $b^{*}$. A sufficiently large increase in the price increases the value of skills by so much that the earnings of the old go up, even with the reduced effort. For the same reason, the impact on wage growth $w_{2}-w_{1}$ is in general ambiguous, but if distortions are not too large then constrained borrowing is certain to depress wage growth. Intuitively, when it is not possible for young workers to pay sufficiently in money 
in exchange for future returns to experience, then a combination of higher effort early on in the career and slacking off later tend to diminish the monetary return to experience.

If the ability to borrow is decreased, then workers in a sector with learning would be made worse off, so the price of output there (and thus the value of experience) has to increase to keep attracting workers to the sector. This is a terribly inefficient way of attracting workers into the sector because most of the resulting increase in incomes inevitably accrues to workers later in the career when they are already paid above their lifetime average and thus have a relatively low marginal utility for consumption.

\section{Wage Profiles in a Cross-Section of Industries}

The model implies that wage profiles of (initially) identical workers will differ across industries depending on the combination of learning and production costs. In this section, the cross-industry variation in wage profiles is related to technological characteristics $(\delta, \phi)$. The wage profile is described here by two values: average wage, $\bar{w}=\left(w_{1}+w_{2}\right) / 2$, and wage growth, $\dot{w}=\left(w_{2}-w_{1}\right)$. For simplicity, the liquidity constrained case will be analyzed at $b=0$. The results are summarized by the next two propositions.

Proposition 5 The average wage and wage growth are both increasing in production cost $(\phi)$; both effects are stronger in the presence of a borrowing constraint.

Mathematically, $\mathrm{d} \bar{w}^{0} / \mathrm{d} \phi>\mathrm{d} \bar{w}^{*} / \mathrm{d} \phi>0$ and $\mathrm{d} \dot{w}^{0} / \mathrm{d} \phi>\mathrm{d} \dot{w}^{*} / \mathrm{d} \phi>0$. The proof is in the Appendix.

The differences in average wage (and so in lifetime earnings) between industries reflect the compensating differentials for lifetime effort costs. Costlier jobs give rise to person-level economies of scale: it makes sense to have fewer workers but have them work harder. ${ }^{9}$ In the efficient solution, effort costs are the only

\footnotetext{
${ }^{9} \mathrm{By}$ the same argument, high effort is also an efficient way to economize on human capital in careers with costly education. In terms of the current model, $\phi$ could include the service of debt
} 
source of compensating differentials. In the liquidity constrained case, a second source of compensating differentials arises from imperfect consumption smoothing. Careers with learning require young workers to consume less than the lifetime average, which in turn requires a higher average wage to compensate for any given differential in lifetime effort costs.

Proposition 6 With unconstrained borrowing, the average wage is decreasing in learning $(\delta)$, without borrowing the average wage is increasing in $\delta$. Wage growth is always increasing in $\delta$.

Mathematically, $\mathrm{d} \bar{w}^{0} / \mathrm{d} \delta>0>\mathrm{d} \bar{w}^{*} / \mathrm{d} \delta$ and $\mathrm{d} \dot{w}^{0} / \mathrm{d} \delta>0, \mathrm{~d} \dot{w}^{*} / \mathrm{d} \delta>0$. The proof is in the Appendix.

When workers are liquidity constrained, an increase in $\delta$ lowers the consumption when young and increases it when old; since more uneven consumption lowers lifetime utility, a higher lifetime wage (via higher price of output) is needed to compensate in equilibrium.

It may seem odd that, in the unconstrained case, equilibrium earnings are decreasing in the steepness of the learning curve-after all, the intuition of convex effort costs suggests that it is cheaper to provide an even level of effort throughout the career. This is a case of the paradox of price theory by which any change in the relative price of two assets that leaves the total value of the assets unchanged will allow for a higher utility after reoptimization. As long as the total value of an individual's endowment of labor is held fixed, a non-constant productivity across periods will allow the worker to get onto a higher indifference curve-and this in turn requires a lower $p$ to bring the worker back to the original utility level.

The presence of a binding liquidity constraint does not imply that the starting salary must be lower in a career with learning and positive wage growth than in a career without learning. I.e., a profession may well be suffering from the "overwork-overpay" distortion, even if young workers there earn more than in for education incurred prior to the first period of production. 
an alternative sector that is not affected by liquidity constraints. While a steeper learning curve implies a lower starting salary other things equal, a profession with a higher $\delta$ and a higher $\phi$ can have a higher wage throughout the career, due to the compensating differential for effort levels. ${ }^{10}$

Role of intertemporal elasticity of substitution Logarithmic period utility, and therefore unit-elastic intertemporal substitution, was chosen to yield tractable closed-form solutions for consumption and effort supply. The assumption is not without loss of generality: If, to take the extreme case, the utility function were linear (i.e., had an intertemporal elasticity close to infinity) then the credit constraint would have no bite as workers would not mind accepting an uneven level of consumption. For a sufficiently high intertemporal elasticity the liquidity constrained case begins to behave more like the unconstrained case. More generally, for propositions 2-5 to hold, the intertemporal substitution of elasticity must not be too high. As the additional features brought on by a more general form of a utility function are not particularly instructive, here the results are analyzed at the simple case of unit elasticity. ${ }^{11}$

Effort-dependent learning The effect of experience on productivity was modeled as completely exogenous, so also as independent of effort. In addition to

\footnotetext{
${ }^{10}$ This is true both with and without a borrowing constraint. To see this, consider sectors $A$ and $B$, where $\delta_{B}>\delta_{A}=0$ and $\phi_{B}>\phi_{A}$. Now $\dot{w}_{A}=0$ and, by Propositions 5 and $6, \dot{w}_{B}>0$ and $\bar{w}_{B}>\bar{w}_{A}$ so that $w_{1}^{B}=\bar{w}_{B}-\dot{w}_{B} / 2>w_{1}^{A}=\bar{w}_{A}$, unless $\delta_{B}$ is too high (which could make $\dot{w}_{B}$ so high that the last inequality is violated).

${ }^{11}$ The assumed period utility function (12) is a limiting case of a utility with constant intertemporal elasticity of substitution $\sigma$,

$$
u\left(x_{t}, e_{t}\right)=\alpha \frac{x_{t}^{1-1 / \sigma}-1}{1-1 / \sigma}+(1-\alpha) \frac{\left(1-e_{t}\right)^{1-1 / \sigma}-1}{1-1 / \sigma}, \quad \sigma>1,
$$

where $\log$ utility arises as $\sigma \rightarrow 1$. It is possible to derive implicit threshold levels for $\sigma$, below which propositions $2-5$ hold but these are not particularly instructive and are omitted here.
} 
simplify the model, the purpose of this assumption was to make it clear that the inefficiency is not due to workers investing the wrong amount of effort into learning - there is no active investment in the model. In practice, the level of effort can have an impact on the strength of learning-by-doing, and it can make sense for the young to work harder than the old for the same reasons that it makes sense to get educated when young. The model can be thought of as a limiting case where the effectiveness of learning gets less and less sensitive to the level of first period effort. It has the incidental feature that the efficient effort supply is higher for the old than for the young, since they have the same effort cost function but a higher marginal product for effort. However, the point of the effort-independent learning model is not that the experienced should supply more effort than the experienced, the point is that the market imperfections drive the age profile of effort supply to be more front-loaded than optimal. As long as the equilibrium earnings of the young are lower than the earnings of the old, then the liquidity constraint will induce the young to compete away the anticipated returns to experience with excess effort.

\section{Work Hours Regulations}

Could a rat race between workers who compete for valuable work experience be a justification for policies that shorten the workweek or lengthen vacation time? Effort that can be regulated would probably have to mean time spent at work, which is clearly not the same thing as effort. But suppose that hours worked had a close correspondence with effort, and that it was possible to enforce a cap on hours worked (which may be realistic in professions where work can not be taken home). It turns out that even perfectly enforceable work hour regulation would be counterproductive from welfare point of view.

It is fairly obvious that in the absence of imperfections an effort cap could only do damage. However, it might seem that when effort levels are distorted 
by a liquidity constraint then a cap on effort could have a potentially beneficial impact, at least if it is only binding for the young who are working harder than in the first-best solution. Note that, thanks to the decomposition of the effort supply problem by period, a cap $\hat{e} \in\left[e_{2}^{0}(p), e_{1}^{0}(p)\right)$ would not directly affect the choice of second period effort. The key is to understand that restricting the first-period effort supply will, other things equal, reduce the first-period utility of workers (it was maximized with respect to $e_{1}$ before the cap, after all). Then for the workers' entry condition to keep holding, the price of output must increase. Consumers are thus surely hurt by this regulation. As for older workers, who are working inefficiently little to begin with, the higher price will further reduce their effort supply. (For the same reason, if the cap was initially binding in both periods, then it could paradoxically cause the second period effort supply to fall strictly below the cap.)

With unregulated effort choice, the returns to experience that young workers are unable to pay for are dissipated with as little loss in welfare as possible, as they are allowed to choose how much to "bid" for jobs in terms of effort and how much in terms of lower consumption. Putting a cap on hours worked distorts the choice, and results in an even higher output price. Entering workers still have to buy their way into the industry, to make the employers consider them equally attractive to hire as old workers given their difference in productivity. Lowering the hours worked by all young workers does not eliminate the rat race, because the "race" is essentially against the experienced workers, who do not work as hard to begin with thanks to their higher ability.

\section{Income Taxation}

As is often the case, a system of lump-sum taxes and subsidies could in principle be used to achieve an efficient outcome. Here the fully efficient lump-sum scheme would be particularly simple, if unrealistic: a lump-sum tax equal to the efficient 
price of jobs, $b^{*}$, levied on experienced workers and transferred to the novices in the same industry. More interestingly, even a distortionary income tax can increase efficiency, despite reducing the incentive to work for everyone, including the old who are working too little to begin with.

Consider a linear income tax at rate $\tau$, with the proceeds redistributed as a uniform grant of size $T$ to all workers in the industry. For simplicity, let's assume that the borrowing constraint is complete so that $b=0$. The after-tax earnings and consumption are then

$$
x_{t}=(1-\tau)\left(p \theta_{t} e_{t}-\phi\right)+T, t=1,2 .
$$

Government budget balance requires that

$$
T=\tau p\left(\frac{\theta_{1} e_{1}+\theta_{2} e_{2}}{2}-\phi\right) \text {. }
$$

Individuals choose effort supplies $\left\{e_{1}, e_{2}\right\}$ to maximize utility, while taking as given the wage offers determined by $p$ and the tax policy $\{\tau, T\}$. In equilibrium, the maximized level of lifetime utility must equal the outside opportunity $2 u_{0}$. The effort supplies are derived as in Section 3, but with consumption levels now including a constant term $T$ in both periods instead of the borrowing $b$ for young and the payback $-b$ for old.

$$
\begin{aligned}
1-e_{t}(p, \tau, T) & =\left(\frac{1-\alpha}{p \theta_{t}}\right)\left(z_{t}(p)+\frac{T}{1-\tau}\right) \\
x_{t}(p, \tau, T) & =\alpha\left((1-\tau) z_{t}(p)+T\right)
\end{aligned}
$$

Combining (36) with (35) gives the equilibrium tax revenue per worker:

$$
T^{*}(\tau)=\left(\frac{1-\tau}{1-\alpha \tau}\right) \tau \alpha z(p) .
$$

Taking into account government budget balance in (36) and (37), the equilibrium has

$$
\begin{aligned}
1-e_{t}(p, \tau) & =\left(\frac{1-\alpha}{1-\alpha \tau}\right)\left(\frac{z_{t}(p)+\tau p \alpha\left(\theta-\theta_{t}\right)}{p \theta_{t}}\right), \quad t=1,2, \\
x_{t}(p, \tau) & =\alpha\left(\frac{1-\tau}{1-\alpha \tau}\right)\left(z_{t}(p)+\tau p \alpha\left(\theta-\theta_{t}\right)\right), \quad t=1,2 .
\end{aligned}
$$


Without taxation these reduce to the previous solutions (24), with $b=0$. As could be expected, individuals respond to an increase in the income tax rate by consuming more "leisure" and less material goods.

Finally, the output price $p$ is implicitly determined by the workers' free entry condition:

$$
p(\tau)=\left\{p \text { st. } U\left(x_{1}(p, \tau), x_{2}(p, \tau), e_{1}(p, \tau), e_{2}(p, \tau)\right)=2 u_{0}\right\}
$$

Recall that social welfare in this model is only affected by the price of output, as the lifetime utility of workers and the profits of firms are fixed in equilibrium by the free entry conditions.

Proposition 7 In the presence of a binding liquidity constraint, the welfare maximizing linear income tax rate is positive.

In other words, $p(\tau)$ is minimized by a strictly positive $\tau$. The proof is in the Appendix. For the intuition, recall that at the starting point $\tau=0$ the effort is too high for the young and too low for the old, vice versa for consumption, relative to the efficient benchmark. Due to free entry, when workers choose effort levels to maximize their individual utility they end up choosing the effort supplies that minimize the price of output-subject to the worker borrowing constraint. Near $\tau=0$ the distortion in effort supply caused by an increase in the tax rate is of second order, as welfare has already in effect been maximized with respect to individual effort supplies subject to the borrowing constraint. However, an increase in tax rate near $\tau=0$ causes a first order increase in tax revenue, resulting in a costless net transfer of funds from the highly paid old workers to less paid young workers. ${ }^{12}$ Being revenue neutral, this tax has the same effect on lifetime utility as an increase in the ability to borrow. However, the optimal economy-wide tax rate would have to be a compromise that takes into account the heterogeneity of sectors, but this issue is beyond the one-sector model.

\footnotetext{
${ }^{12}$ Because the derivative $\partial T^{*}(\tau) / \partial \tau$ evaluated at $\tau=0$ is simply $\alpha z(p(0))>0$.
} 
A sufficiently high tax rate will of course hurt welfare as the effort-reducing effect begins to dominate. It can be shown that the optimal tax rate is increasing towards unity in production costs $\phi$ and in learning effect $\delta$ (proof omitted). Intuitively, the net transfer attempts to mimic the borrowing $b^{*}$ that unconstrained workers would choose to do, and $b^{*}$ is increasing in $\phi$ and $\delta$. Interestingly, the optimal tax rate could well be in the decreasing part of the Laffer curve. This is because the optimal tax rate can, for sufficiently high distortions, be arbitrarily close to one but the location of the top of the Laffer curve is a constant that only depends on preferences (the relative disutility of effort). ${ }^{13}$

\section{Limitations and Further Issues}

To keep the analysis tractable, despite the combination of labor and product markets, several important traits of actual labor markets were abstracted away in the model. The focus was on deriving wage and effort differences across experience levels and industries, so individuals were modeled as completely homogeneous and information as perfect. In practice, on-the-job enhancement of human capital often comes in the form of better information-for example, as better knowledge about the productivity of the match between an individual and an occupation. Even though workers may be ex-ante homogeneous, learning about individual types entails an inherent heterogeneity of talent. In the case of such informationbased human capital the expected returns to experience arise from the option value of quitting, even if true productivity is not affected by experience. For example, in Jovanovic (1979), the value of the match between a worker and a firm is a form of firm-specific human capital that is acquired passively on the job. In a separate paper (Terviö 2009) I explore the implications of worker liquidity constraints under public on-the-job learning about an industry-specific ability-i.e. about the

\footnotetext{
${ }^{13}$ Maximizing (38) with respect to the tax rate reveals that the top of the Laffer curve is at $\widehat{\tau}=(1-\sqrt{1-\alpha}) / \alpha$.
} 
quality of the match between a worker and an industry. The main result is that if untried workers are unable to pay up-front for jobs, then there will be too little experimentation with new talent, leading to a selection of too many mediocre workers into the industry, and to an amplification of rents to high talent. That paper abstracts away from effort, but if the model is augmented with effort choice, than the expected returns to experience will be partly dissipated through excess effort by young workers for reasons analogous to those found in the current paper.

In the life-cycle models of human capital investment and labor supply, see especially Ben Porath (1967) and Blinder and Weiss (1976), the creation of human capital requires active investment from the worker and it also depreciates over time unless replenished by new investments. In such setups workers have an incentive to let their human capital diminish near the end of their career, because the return to investment into human capital gets lower as the career time left for using it gets shorter. Due to the two-period careers, the current model is not equipped to analyze such life-cycle issues, but a model with continuous time could yield interesting insights. The opportunity cost of jobs that is central to the current model would introduce two potentially distorted margins into the life-cycle model: the choice of when to switch from education into a job, and when to retire. The presence of labor market imperfections can result in a socially inefficient choice at both of these margins. In particular, old workers in occupations with strong learning effects would be prone to retire inefficiently late, because they don't take into account the value of their job in creating human capital through learning and the youngest workers are unable to buy them out. At the other margin, formal education can displace some learning-by-doing even where the latter would be a technologically more efficient way of improving worker productivity. Such overeducation can result in professions where education is less costly than the (unconstrained) implicit price of jobs.

While only general human capital is considered in this paper, the classification into active and passive forms of investment also holds for firm-specific human 
capital. As first pointed out by Becker (1962), if human capital is firm-specific, then firms are willing to pay for on-the-job training. For the same reason, distortions to effort supply would be less of a problem if the learning-by-doing were firm-specific. ${ }^{14}$ However, investment into firm-specific human capital still has its own problems. The value of firm-specific human capital is subject to bargaining between the firm and the worker, with the usual potential for hold-up, as well as for losses from exogenous separations. Firms will be willing to pay for the costs only as much as they can expect to capture the returns to firm-specific human capital.

\section{Conclusion}

Investment into human capital is "active" whenever the production of human capital entails a trade-off between current and future output; for example, training implies an investment into the worker that an already trained worker would not require, and active on-the-job learning may require a different use of time between tasks than required by the maximization of current output. ${ }^{15}$ The literature on the interplay of market imperfections and on-the-job enhancement of human capital has focused on active investments, probably because there the investment cost is directly measurable. In this paper I showed how completely passive enhancement of human capital-learning-by-doing that is a pure by-product of workinggenerates inefficiencies under the same standard labor market imperfections that hamper the efficient provision of active investments.

\footnotetext{
${ }^{14}$ Additional imperfections, such as asymmetric information, can give firms incentives to pay for some general training as well, see e.g., Katz and Ziderman (1990), and Acemoglu and Pischke (1999). Additional imperfections serve to make the general human capital effectively more firmspecific. However, Neal (1995) provides evidence that industry-specific (rather than firm-specific) human capital explains most of the wage-tenure relation.

${ }^{15}$ This distinction is due to Killingsworth (1982), who combined (pure) training and (pure) experience in a Ben Porath type of model.
} 
Learning-by-doing leads to predictable returns to experience, and in a perfect market, the economic returns to experience in each occupation would be determined solely by technological factors - costs of production, malleability of skills. At the same time, young workers should be, ceteris paribus, indifferent between entering alternative professions that promise different returns to experience. Large returns to experience amount to very steep age-earnings profiles, so for that indifference to hold, earnings in professions where learning-by-doing is particularly important should start out very low, possibly negative.

When young workers can neither commit to long-term wage contracts nor self finance the costs of production, it may be impossible to sustain the high monetary returns to experience that would reflect the technologically efficient returns to experience. In this case the returns to experience are dissipated via an inefficient allocation of consumption and leisure over the lifetime: basically by having to work harder and consume less when young. The flip side of this rat race among young workers is that the older workers underutilize their human capital: they do not work hard enough. The inefficient use of effort in the industry increases the price of output, so the wealth endowment of the experienced workers is in effect increased, causing them to consume more leisure.

The cost of employing an inexperienced worker instead of an experienced worker is a pure opportunity cost: the latter would produce a higher level of output in the same job. This cost, and therefore the level of borrowing required by young workers for efficiency to be achieved, is by no means limited by the level of outside wages - rather, the young workers may have to finance a significant fraction of the costs of complementary factors of production. To be sure, if the impact of learning-by-doing on productivity is small, then a modest wage discount for the young would be sufficient for the industry to function efficiently. But if the productivity disadvantage of inexperienced workers is sufficiently large, then they would in effect have to pay for most of the costs production.

Simply observing higher effort in some sectors is of course by no means a 
proof of inefficiency. It is in the society's interest that workers in industries with a relatively high marginal product of effort work the hardest, and this higher effort must be compensated by a higher level of consumption. (By the same token, the more able should also work harder. Disentangling the compensating differential for optimal effort from returns to education, experience, and scarce talent, is of course the typical hard problem facing empirical labor economics and is in no way alleviated by this paper.) In a perfect market the "compensating differentials" between occupations would reflect differences in optimal levels of effort. The real constraint imposed by the lack of long-term wage contracts is that the compensating differentials between alternative careers - the role of which is to equalize the utility over the lifetime-must be paid over the career in lockstep with the age-profile of output, which in turn depends on the nature of learning-by-doing and the resulting age profile of productivity in each profession. Inefficiencies will arise in professions where individuals are unable to absorb the technologically optimal age profile of productivity into their age profile of net cash flows.

In the absence of observations of how labor market outcomes would react to different institutions, the results here are, of course, only suggestive. While the approach has been theoretical, and a clean empirical evaluation of the inefficiencies would perhaps require a rare natural experiment, I hope the insights are helpful in interpreting differences in earnings and age-earnings profiles across professions. Individual ability to incur debt is limited, but when it comes to the ability to experience marginal disutility from additional late night hours of work then sky is the limit. So what do we really see when we see young people working hard towards high incomes later in life? As it stands, large amounts of welfare may be dissipated at late hours at countless offices. And if it is the case that the role of on-the-job creation of human capital is becoming more important over time in high-skill sectors, then we can expect young professionals to be working harder and harder, in expectation of relatively higher and higher wages, but to not necessarily be any better off than earlier generations in the same professions. 


\section{Appendix}

Proof. of Proposition 5. First, implicitly differentiate (25) and apply the envelope theorem to eliminate terms involving $\partial \tilde{V} / \partial e_{t}$, to obtain

$$
\begin{aligned}
\frac{\mathrm{d} p}{\mathrm{~d} \phi} & =\frac{u_{x}\left(x_{1}^{0}\right)+u_{x}\left(x_{2}^{0}\right)}{u_{x}\left(x_{1}^{0}\right) y_{1}^{0}+u_{x}\left(x_{2}^{0}\right) y_{2}^{0}} \\
& =\left(\frac{1}{\theta}\right) \frac{u_{x}\left(x_{1}^{0}\right)+u_{x}\left(x_{2}^{0}\right)}{u_{x}\left(x_{1}^{0}\right)(1-\delta) e_{1}^{0}+u_{x}\left(x_{2}^{0}\right)(1+\delta) e_{2}^{0}}>\frac{1}{\theta}
\end{aligned}
$$

where $x_{1}^{0}<x_{2}^{0}$ and $e_{t}<1$ were used to justify the inequality. Similarly, in the efficient case,

$$
\frac{\mathrm{d} p^{*}}{\mathrm{~d} \phi}=\frac{2 u_{x}\left(x^{*}\right)}{u_{x}\left(x^{*}\right)\left(y_{1}^{*}+y_{2}^{*}\right)}=1 / \bar{y}^{*}
$$

Since $\bar{y}^{*}=\theta\left(e_{1}+e_{2}\right) / 2<\theta$ (because $e_{t}<1$ ) it follows that $\mathrm{d} p^{*} / \mathrm{d} \phi<$ $1 / \theta<\mathrm{d} p / \mathrm{d} \phi$. The change in average wage $\bar{w}=\alpha z(p)$ caused by an increase in production cost is

$$
\frac{\partial \bar{w}^{0}}{\partial \phi}=\alpha\left(\frac{\mathrm{d} p^{0}}{\mathrm{~d} \phi} \theta-1\right)
$$

To see that this is positive in the efficient case, note that average wage must satisfy $\bar{w}=p \bar{y}-\phi$, so that $\bar{y}=(\alpha(p \theta-\phi)+\phi) / p$. Thus

$$
\frac{\partial \bar{w}^{*}}{\partial \phi}=\alpha\left(\frac{p^{*} \theta}{\alpha\left(p^{*} \theta-\phi\right)+\phi}-1\right)=\alpha\left(\frac{(1-\alpha)\left(p^{*} \theta-\phi\right)}{\alpha\left(p^{*} \theta-\phi\right)+\phi}\right)>0 .
$$

In the constrained case, $\mathrm{d} p / \mathrm{d} \phi>1 / \bar{y}$, and $\bar{y}<\bar{y}^{*}$, so $\partial \bar{w} / \partial \phi>\partial \bar{w}^{*} / \partial \phi$. As for changes in wage growth, the signs can be seen by direct inspection:

$$
\begin{aligned}
& \frac{\partial\left(\dot{w}^{0}\right)}{\partial \phi}=\alpha \delta \frac{\mathrm{d} p^{0}}{\mathrm{~d} \phi} \theta>0, \\
& \frac{\partial\left(\dot{w}^{*}\right)}{\partial \phi}=\delta \frac{\mathrm{d} p^{*}}{\mathrm{~d} \phi} \theta>0 .
\end{aligned}
$$


Proof. of Proposition 6. Average wage is $\alpha(p \theta-\phi)$, so the change only depends on $\mathrm{d} p / \mathrm{d} \delta$. Implicitly differentiating the equilibrium condition (25) yields

$$
\frac{\mathrm{d} p^{0}}{\mathrm{~d} \delta}=p^{0} \theta \frac{u_{x}\left(x_{1}^{0}\right) e_{1}^{0}-u_{x}\left(x_{2}^{0}\right) e_{2}^{0}}{u_{x}\left(x_{1}^{0}\right) y_{1}^{0}+u_{x}\left(x_{2}^{0}\right) y_{2}^{0}}>0
$$

where positivity follows from $u_{x}\left(x_{1}^{0}\right)>u_{x}\left(x_{2}^{0}\right)$ and $e_{1}^{0}>e_{2}^{0}$ by inspection of (23). In the unconstrained case, where $x_{1}=x_{2}$, this is simply

$$
\frac{\mathrm{d} p^{*}}{\mathrm{~d} \delta}=-p^{*} \theta \frac{e_{2}^{*}-e_{1}^{*}}{y_{1}^{*}+y_{2}^{*}}<0
$$

where $e_{2}^{*}>e_{1}^{*}$ by inspection of (16).

The change in wage growth is obtained by substituting in $e_{t}^{0}$ from (23) to $\dot{w}=$ $(p / 2)\left(\theta_{2} e_{2}-\theta_{1} e_{1}\right)$, and differentiating. In the constrained case this gives

$$
\frac{\partial \dot{w}^{0}}{\partial \delta}=\alpha \theta\left(\delta \frac{\mathrm{d} p^{0}}{\mathrm{~d} \delta}+p^{0}\right)>0
$$

where positivity follows from $\mathrm{d} p^{0} / \mathrm{d} \delta>0$ by (48). Similarly, in the constrained case, except substituting in $e_{t}^{*}$ from (16), results in

$$
\frac{\partial \dot{w}^{*}}{\partial \delta}=\theta\left(\delta \frac{\mathrm{d} p^{*}}{\mathrm{~d} \delta}+p^{*}\right)>0 .
$$

To see that (51) is positive, substitute in (49) and simplify to obtain

$$
\begin{aligned}
\theta\left(-\delta \frac{p^{*} \theta\left(e_{2}^{*}-e_{1}^{*}\right)}{2 \bar{y}^{*}}+p^{*}\right) & =\frac{p^{*} \theta}{2 \bar{y}^{*}}\left(-\delta \theta\left(e_{2}^{*}-e_{1}^{*}\right)+2 \bar{y}^{*}\right) \\
& =\frac{p^{*} \theta^{2}}{2 \bar{y}^{*}}\left(e_{2}^{*}+e_{1}^{*}\right)>0
\end{aligned}
$$

Near $\delta=0$, where there is no distortion $\left(p^{0} \approx p^{*}\right)$, the changes reduce to $\alpha \theta p^{*}$ with and $\theta p^{*}$ without the constraint. For sufficiently high $\delta, \mathrm{d} \dot{w}^{0} / \mathrm{d} \delta>\mathrm{d} \dot{w}^{*} / \mathrm{d} \delta$ because, unlike $p^{*}, p^{0}$ grows without limit as $\delta \rightarrow 1$.

Proof. of Proposition 7. Insert the equilibrium effort and consumption levels from (39 and (40) into the worker entry condition, which determines the price of output 
in (41). Using the closed-form of the utility function from (12) and simplifying gives the implicit definition of the equilibrium price $p(\tau)$ as

$$
2[A(\alpha)+\alpha \log (1-\tau)-\alpha \log (1-\alpha \tau)]+\sum_{t=1}^{2} \log \left(z_{t}+\tau p \alpha\left(\theta-\theta_{t}\right)\right)=2 u_{0},
$$

where the constant term is $A(\alpha) \equiv \alpha \log \alpha+(1-\alpha) \log (1-\alpha)$. This implies that $p(\tau) \rightarrow \infty$ as $\tau \rightarrow 1$. Differentiating with respect to $p$ and $\tau$ and solving for the total differential yields the slope

$$
\frac{d p}{d \tau}=-\left(\frac{2 \alpha\left(\frac{1}{1-\alpha \tau}-\frac{1}{1-\tau}\right)+\sum_{t=1}^{2}\left(\frac{p \alpha\left(\theta-\theta_{t}\right)}{z_{t}+\tau p \alpha\left(\theta-\theta_{t}\right)}\right)}{\sum_{t=1}^{2}\left(\frac{\theta_{t}+\tau \alpha\left(\theta-\theta_{t}\right)}{z_{t}+\tau p \alpha\left(\theta-\theta_{t}\right)}-\frac{(1-\alpha)}{p}\right)}\right) .
$$

Now use $\theta-\theta_{1}=\theta \delta=-\left(\theta-\theta_{2}\right)$. Evaluated at $\tau=0$, (54) becomes

$$
\left.\frac{d p}{d \tau}\right|_{\tau=0}=-\left(\frac{\alpha p \theta \delta\left(\frac{1}{z_{1}}-\frac{1}{z_{2}}\right)}{\sum_{t=1}^{2}\left(\frac{\theta_{t}}{z_{t}}-\frac{(1-\alpha)}{p}\right)}\right)<0 .
$$

Inside the parenthesis, the numerator is positive because $z_{1}<z_{2}$. The denominator is positive because $\theta_{t} / z_{t}>(1-\alpha) / p \Longleftrightarrow p \theta_{t}>(1-\alpha)\left(p \theta_{t}-\phi\right)$. Thus the overall sign is the minus sign from outside the parenthesis.

\section{References}

ACEMoglu, DARon And Jörn-STEFFEn PischKe (1999): "Beyond Becker: Training in Imperfect Labor Markets.” Economic Journal, 109, pp. 112-142.

BECKER, GARY S (1962): "Investment in Human Capital: A Theoretical Analysis.” Journal of Political Economy, 70, pp. 9-49.

Ben Porath, Yoram (1967): "The Production of Human Capital and the Life Cycle of Earnings," Journal of Political Economy, 75(4), 352-365.

Blinder, Alan S AND Yoram WeISS (1976): "Human Capital and Labor Supply: A Synthesis," Journal of Political Economy, 84(3), 449-472. 
Ghatak, Maitreesh; Massimo Morelli And Tomas Sjöström (2001): “Occupational Choice and Dynamic Incentives." Review of Economic Studies, 68, pp. 781-810.

HAMERMESh, DANIEl S AND JOEL Slemrod (2006): “The Economics of Workaholism: We Should not Have Worked on This Paper." Working paper.

Holmström, Bengt (1982): "Managerial Incentive Problems-A Dynamic Perspective.” Reprinted in Review of Economic Studies (1999), 66(1), pp. 169-182.

JOVANOVIC, BOYAN (1979), "Job Matching and the Theory of Turnover.” Journal of Political Economy, 87, pp. 972-990.

KATZ, ELIAKIM AND AdRIAN Ziderman (1990), Investment in General Training: the Role of Information and Labor Mobility. Economic Journal, 100, pp. 1147-1158.

Killingsworth, MARK R (1982): "Learning by Doing and Investment in Training: A Synthesis of Two Rival Models of the Life Cycle." Review of Economic Studies, 49(2), pp. 263-271.

LANDers, Renee M; JAMes B Rebitzer, And Lowell J TAYlor (1996): "Rat Race Redux: Adverse Selection in the Determination of Work Hours in Law Firms.” American Economic Review, 86(3), pp. 329-48.

NeAL, DEREK (1995): "Industry-Specific Human Capital: Evidence from Displaced Workers.” Journal of Labor Economics. 13(4), pp. 653-677.

Rosen, SHERWIN (1972): "Learning and Experience in the Labor Market," Journal of Human Resources, 7(3), 326-342.

SCHOR, JULIET B (1992): "The overworked American: the unexpected decline of leisure." Basic Books.

TERVIÖ, MARKO (2009): "Superstars and Mediocrities: Market Failure in the Discovery of Talent." Forthcoming in the Review of Economic Studies. 